\title{
Implementação do conceito Capacidade de Diluição de Efluentes no modelo de qualidade da água QUAL-UFMG: estudo de caso no Rio Taquarizinho (MS)
}

\section{Implementation of the concept Capacity for Dilution of Effluents in the water quality model QUAL-UFMG: a case study in Taquarizinho River (MS)}

\author{
Anderson Teodoro \\ Engenheiro Ambiental. Doutorando do Programa de Pós-Graduação em Tecnologias Ambientais da Universidade Federal de Mato Grosso do Sul (UFMS) - \\ Campo Grande (MS), Brasil.
}

\section{Carlos Nobuyoshi Ide}

Engenheiro Civil. Doutor em Recursos Hídricos e Saneamento Ambiental pela Universidade Federal do Rio Grande do Sul (UFRGS) - Porto Alegre (RS) Brasil. Professor associado do Departamento de Hidráulica e Transportes da UFMS - Campo Grande (MS), Brasil.

Maria Lúcia Ribeiro

Engenheira Química. Doutora em Recursos Hídricos e Saneamento Ambiental pela UFRGS - Porto Alegre (RS), Brasil. Professora associada do Departamento de Hidráulica e Transportes da UFMS - Campo Grande (MS), Brasil.

\section{Synara Aparecida Olendzki Broch}

Engenheira Civil. Doutora em Desenvolvimento Sustentável pela Universidade de Brasília (UNB) - Brasília (DF), Brasil. Professora visitante do Programa de Pós-Graduação em Tecnologias Ambientais da UFMS - Campo Grande (MS), Brasil.

\section{Jhonatan Barbosa da Silva}

Engenheiro Ambiental. Doutorando do Programa de Pós-Graduação em Tecnologias Ambientais da UFMS - Campo Grande (MS), Brasil.

\section{Resumo}

A plataforma em Excel QUAL-UFMG é uma ferramenta de fácil utilização e grande aplicabilidade na modelagem da qualidade da água de rios. Para uma melhor integração do modelo com o gerenciamento de recursos hídricos, o objetivo do trabalho foi incorporar às planilhas de simulação algumas equações para determinação de vazão de diluição e cobrança pelo lançamento de efluentes. Foram simulados cenários hipotéticos de qualidade da água para estimar a capacidade de autodepuração e diluição de efluentes em um estudo de caso no Rio Taquarizinho. O modelo foi capaz de estimar as vazões de diluição requeridas pelos lançamentos e contabilizar os custos dos mesmos variando-se as vazões de referência, enquadramento e carga orgânica lançada no rio. Concluiu-se que o Rio Taquarizinho possui uma elevada capacidade de autodepuração e que suas águas são capazes de suportar a instalação de empreendimentos de grande porte, como matadouros e curtumes.

Palavras-chave: qualidade da água; modelagem matemática; gerenciamento de recursos hídricos.

\begin{abstract}
The platform QUAL-UFMG on Excel is a tool simple to use with wide applicability to modeling the water quality of rivers. To better integrate the model with the management of water resources, the aim of this study was to incorporate in the simulation spreadsheets some equations for determination of dilution and recovery by the effluent discharge. Hypothetical water quality scenarios were simulated to estimate the capacity of self-depuration and dilution of effluent in a case study in Taquarizinho River. The model was able to estimate the flows required by dilution effluents and account for costs in varying the reference flows, class of water and organic load released into the river. It was concluded that Rio Taquarizinho has a high capacity for self-depuration, and that its waters are capable of supporting the installation of large-scale enterprises such as slaughterhouses and tanneries.
\end{abstract}

Keywords: water quality; mathematical modeling; water resources management. 


\section{Introdução}

Devido aos diversos usos, diretos e indiretos da água, a necessidade de preservação e recuperação de recursos hídricos vem a cada dia se tornando mais evidente. A poluição dos corpos de água é um problema mundial e o seu controle é considerado um dos grandes desafios da gestão dos recursos hídricos, não só no Brasil, como no mundo.

O incremento do uso da água tem consequências diretas para a redução das vazões dos rios, causando uma menor capacidade de diluição autodepuração (PAREDES; ANDREU; SOLERA, 2010). A água é um recurso finito e precisa ser preservado, tornando fundamental o estudo da sua qualidade para uma eficiente gestão dos recursos hídricos.

Dentre os instrumentos de gestão de recursos hídricos dispostos na Lei no .9 .433 de 8 de Janeiro de 1997, que institui a Política Nacional de Recursos Hídricos, estão a outorga dos direitos de uso da água e a cobrança por tal uso. A outorga de direito de uso da água é o ato governamental que autoriza ou concede determinado volume a ser derivado ou usado, de manancial superficial ou subterrâneo, para uma ou diversas finalidades, com o objetivo de assegurar o controle quantitativo e qualitativo dos usos da água e o efetivo exercício dos direitos de acesso à mesma (BRASIL, 1997).

A cobrança visa ao reconhecimento da água como um bem econômico e a incentivar a racionalização de seu uso, além de arrecadar recursos para financiamentos de projetos do plano de recursos hídricos. Seguindo a Lei n. 9.433/97 e a Resolução nº. 48/2005 do CNRH, todo lançamento de efluente sujeito à outorga é passível de cobrança, sendo observado o volume lançado e seu regime de variação, como também as características físico-químicas, biológicas e de toxicidade.

As referências bibliográficas de outorga para lançamento de efluentes no Brasil são bastante escassas. Na maioria dos casos, as metodologias de outorga baseiam-se em propostas como as de Ribeiro e Lanna (2003), com identificação dos efluentes lançados em cada ponto de controle; identificação da vazão máxima permitida pelo enquadramento; cálculo da vazão necessária para diluir a carga lançada, obedecendo à concentração máxima permitida pelo enquadramento e definição de critérios de racionamento para situação em que a vazão disponível não é suficiente para a demanda.

Um dos trabalhos de grande relevância e que atualmente é utilizado na Agência Nacional de Águas (ANA) é o de Rodrigues (2005), que propôs o SSD RB - Sistema de Suporte a Decisão proposto para a gestão quali-quantitativa dos processos de outorga e cobrança pelo uso da água, visando à articulação aos demais instrumentos da Política Nacional de Recursos Hídricos. O sistema possibilita a cobrança pelo uso da água com grande eficácia, com a capacidade de racionar o custo atribuído ao uso e induzir a uma alocação eficiente dos recursos hídricos.
Uma das principais aplicações dos sistemas de suporte à decisão e modelagem matemática da qualidade da água é sua utilização como ferramenta de gestão dos recursos hídricos em uma bacia hidrográfica. O modelo utilizado deve ser capaz de realizar simulações para diferentes cenários de desenvolvimento na bacia, sendo necessário ajustá-lo às condições naturais através de dados de monitoramento. Realizado o ajuste do modelo, esse passará a indicar em qual situação é importante concentrar esforços no planejamento e na tomada de decisões dentro da bacia (LARENTIS, 2004).

Existem algumas experiências pioneiras de cobrança pelo lançamento de efluentes no Brasil que alcançaram certo êxito, como nas bacias do Rio Paraíba do Sul, bacia dos Rios Piracicaba, Capivari e Jundiaí e mais recentemente na bacia do São Francisco. Entretanto, as cobranças realizadas não contemplam a diluição de efluentes, apenas o seu lançamento (cobra-se pela quantidade de matéria orgânica lançada). Nos trabalhos realizados por Kelman (1997), e aprimorados por Silva e Monteiro (2004), as análises dos pedidos de outorga pelo lançamento de efluentes podem ser feitas de maneira que as interferências qualitativas no corpo de água se transformam em equivalentes quantitativos.

A essência da gestão da demanda de água é fornecer métodos para resolver o problema dos usuários de água (DA-PING; HONG-YU; DAN, 2011). Modelos de qualidade da água são importantes ferramentas para a gestão eficaz dos sistemas hídricos e para a simulação e otimização dos regimes de descarga. Além disso, podem ser utilizados para estabelecer procedimentos de vigilância e auxílio no processo de tomada de decisão para que os objetivos ambientais possam ser respeitados, com a definição de margens de segurança adequadas a um custo realista (DA-PING; HONG-YU; DAN, 2008).

A plataforma em Excel QUAL-UFMG desenvolvida por von Sperling (2007) é baseada no modelo clássico QUAL2E. É uma planilha versátil, de modelagem unidimensional e fácil utilização, capaz de simular a reaeração atmosférica e seus efeitos no balanço de oxigênio dissolvido, o decaimento de matéria orgânica e coliformes, além de abranger as séries de fósforo e nitrogênio. O QUAL-UFMG possui uma estrutura muito parecida com a do QUAL2E, excluindo-se o componente algas de sua modelagem por motivos de simplificação técnica e também pela pequena importância das mesmas na simulação de ambientes lóticos.

Como o modelo QUAL-UFMG não executa o cálculo das vazões de diluição e um balanço qualiquantitativo no lançamento de efluentes, o presente trabalho buscou implementar esse conceito com a inserção de equações capazes de determinar vazões de diluição e custos pelo lançamento de efluentes no presente modelo, baseando-se em conceitos pioneiros utilizados pela Agência Nacional de Águas, através de um estudo de caso no Rio Taquarizinho. 


\section{Metodologia}

\section{Área de estudo}

A área de estudo é a Bacia do Rio Taquarizinho (Figura 1), sub-bacia da Bacia do Rio Taquari, que é uma das áreas mais impactadas da região do Pantanal e de crescente discussão a respeito dos impactos ambientais existentes, suas consequências e possíveis soluções futuras. A Bacia do Taquari, por sua vez, é sub-bacia da Bacia do Alto Paraguai (BAP), onde se encontra o Pantanal Sul-Mato-Grossense. A Figura 1 mostra a localização da bacia do Rio Taquarizinho.

Na bacia do Rio Taquarizinho, destaca-se o uso de fertilizantes e pesticidas nas lavouras, que contribuem para a degradação da biota aquática do rio principal, principalmente pelas chuvas subsequentes à aplicação dos agroquímicos, promovendo a lavagem superficial do solo. A interferência antrópica na região é constatada logo após os períodos chuvosos (novembro a março), devido ao carreamento de altas cargas de concentrações de poluentes ao rio.

\section{Seções de Monitoramento}

Foram realizadas medições de vazão e coletas de amostras de água ao longo do Rio Taquarizinho e dos seus principais afluentes: Córrego Matadeira, Córrego Boa Sentença e Córrego Palha. Para cada afluente foi escolhida uma seção a montante da confluência com o curso principal e, no curso principal, foram escolhidas mais cinco seções, sendo uma na nascente do Rio Taquarizinho, uma a montante da confluência de cada um dos afluentes citados acima e uma correspondente à seção

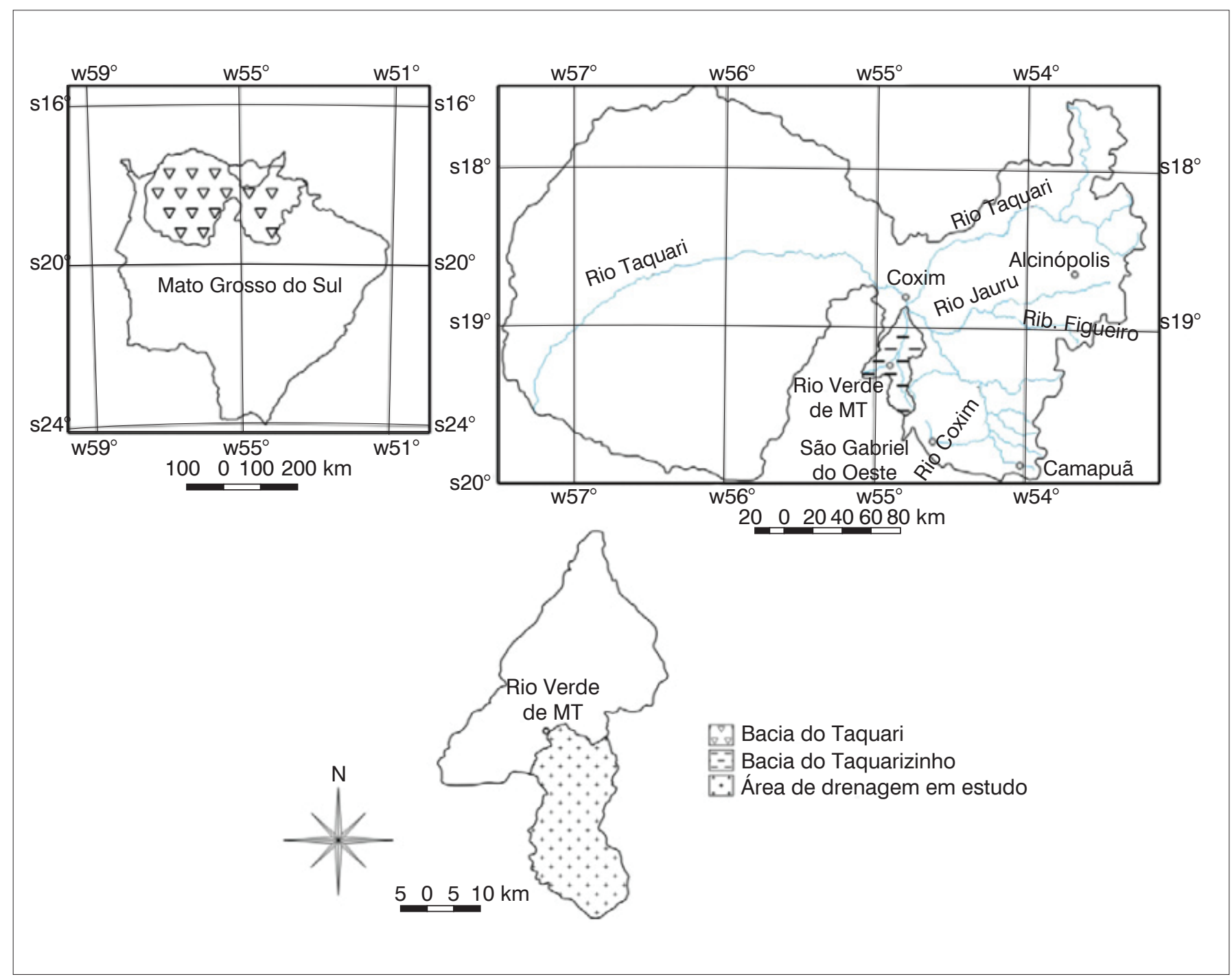

Figura 1 - Mapa de localização da área de estudo na Bacia do Alto Paraguai. 


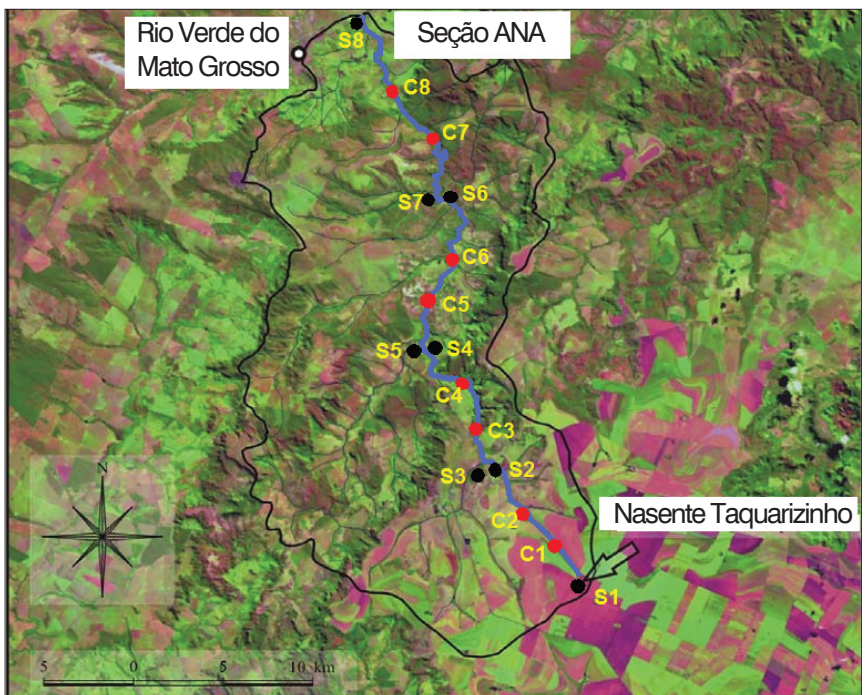

Seções de monitoramento

Pontos de coleta para calibração

Figura 2 - Seções de monitoramento e pontos para calibração.

de monitoramento da ANA (seções de S1 à S8). Na Figura 2 é possível identificar a localização de cada uma dessas seções.

Os pontos C1, C2, C3, C4, C5, C6, C7 e C8 na Figura 2 foram escolhidos entre as seções citadas acima para ajuste e calibração dos coeficientes de decomposição $\left(k_{d}\right)$ e de reaeração $\left(k_{2}\right)$.

\section{Dados de campo}

Para a calibração do modelo e obtenção de cenários futuros são necessários alguns parâmetros hidráulicos e de qualidade da água. Esses parâmetros foram determinados nos trabalhos de campo em período de seca da região: medições de velocidade e vazão; coleta de amostras para análise de oxigênio dissolvido (OD), depois de fixado em campo com solução de sulfato manganoso e solução álcali-iodeto-azida; demanda bioquímica de oxigênio (DBO); medição de temperatura das águas.

As medições de velocidade foram realizadas com molinete hidrométrico. A área molhada da seção foi determinada por meio da batimetria, medindo-se também a distância entre cada vertical que depende da largura do rio. Esse processo foi realizado seguindo a metodologia proposta pelo Departamento Nacional de Águas e Energia Elétrica (DNAEE, 1967).

Para a determinação de oxigênio dissolvido e demanda bioquímica de oxigênio as amostras foram coletadas nas seções de monitoramento e também nos pontos para calibração citados anteriormente. As análises foram realizadas no Laboratório de Qualidade de Água (LAQUA), da Universidade Federal de Mato Grosso do Sul (UFMS), segundo os métodos analíticos 5220 C, 5210 B e 2550 B do Standard Methods for the Examination of Water and Wastewater (APHA; AWWA; WEF, 2005) para OD, $\mathrm{DBO}_{5}$ e Temperatura do ar e ambiente respectivamente.

\section{Calibração dos coeficientes de decomposição $\left(\mathrm{k}_{\mathrm{d}}\right)$ e reaeração $\left(\mathrm{k}_{2}\right)$}

A calibração dos coeficientes de decomposição $\left(k_{d}\right)$ e reaeração $\left(k_{2}\right)$ foi realizada através do coeficiente de determinação (CD). Esse coeficiente apresenta uma relação entre a soma dos erros ou resíduos ao quadrado e a variância total dos dados observados (Equação 1).

$C D=1-\frac{\sum\left(\mathrm{Y}_{\mathrm{i}_{\text {obs }}}-\mathrm{Y}_{\mathrm{i}_{\text {est }}}\right)^{2}}{\sum\left(\mathrm{Y}_{\mathrm{i}_{\text {obs }}}-\mathrm{Y}_{\mathrm{i}_{\text {med }}}\right)^{2}}$

em que:

$\mathrm{Y}_{\mathrm{i}_{\mathrm{w} \text { s }}}=$ valor do OD ou da DBO observado;

$\mathrm{Y}_{\mathrm{i}_{\mathrm{s}}}=$ valor do OD ou da DBO estimado;

$\mathrm{Y}_{\mathrm{i}_{\mathrm{mat}}}=$ média dos valores observados.

O ajuste dos dados estimados aos dados observados experimentalmente e posterior determinação dos coeficientes calibrados foi feito com auxílio da ferramenta Solver do Microsoft Excel ${ }^{\circledR}$. Para isso, foram utilizados valores de $\mathrm{DBO}_{5,20}$ e oxigênio dissolvido (OD) das amostras de água coletadas entre as seções de monitoramento, espacialmente organizadas e distribuídas para calibração.

O coeficiente de sedimentação $\left(k_{3}\right)$ não foi considerado nas simulações, pois o mesmo pode ter valores inexpressivos para lançamento de efluentes tratados. Assim, a não utilização desse coeficiente não promove diferenças significativas para as condições estabelecidas neste estudo. Além disso, a sua determinação não é tarefa simples devido às dificuldades de se calcular velocidades de sedimentação confiáveis no corpo de água.

\section{Vazões de referência}

As vazões escolhidas para as simulações dos cenários foram a $Q_{95}$, a $Q_{90}$ e a $Q_{m}$, sendo as duas primeiras, juntamente com a $Q_{7,10}$ as mais utilizadas tradicionalmente e bastante recomendadas pela legislação referente ao gerenciamento de recursos hídricos. Foram determinadas através de planilhas em Excel, com uso da função Percentil. Inicialmente pensou-se em utilizar a vazão $Q_{7,10}$. Porém, como a série histórica disponível para o estudo só possuía médias mensais de descarga líquida, esse propósito foi descartado. Para simular as condições médias prevalecentes na bacia durante todo $\mathrm{o}$ ano foi escolhida a vazão média $\mathrm{Q}_{\mathrm{m}}$ (média das vazões médias mensais anuais).

\section{Equações inseridas no modelo QUAL-UFMG}

Como o QUAL-UFMG não contempla a determinação das vazões de diluição requeridas pelos lançamentos no rio, as equações que as 
determinam e os custos anuais por lançamento foram acrescentadas nas planilhas utilizadas na modelagem.

A Equação 2 foi utilizada para determinar a vazão de diluição por lançamento sem considerar a capacidade de autodepuração, inicialmente proposta por Kelman (1997):

$\mathrm{Q}_{\mathrm{dil}}=\mathrm{Q}_{\mathrm{ef}} \times\left(\mathrm{C}_{\mathrm{ef}}-\mathrm{C}_{\text {perm }}\right) /\left(\mathrm{C}_{\mathrm{perm}}-\mathrm{C}_{\text {nat }}\right)$

em que:

$\mathrm{Q}_{\text {dil }}=$ vazão de diluição para determinado parâmetro de qualidade $\left(\mathrm{m}^{3} \cdot \mathrm{s}^{-1}\right)$;

$\mathrm{Q}_{\mathrm{ef}}=$ vazão do efluente que contém o parâmetro de qualidade analisado $\left(\mathrm{m}^{3} \cdot \mathrm{s}^{-1}\right)$

$\mathrm{C}_{\mathrm{ef}}=$ concentração do parâmetro de qualidade no efluente (mg. $\left.\mathrm{L}^{-1}\right)$;

$\mathrm{C}_{\text {perm }}=$ concentração permitida para o parâmetro de qualidade no manancial onde é realizado o lançamento ( $\left.\mathrm{mg} . \mathrm{L}^{-1}\right)$;

$\mathrm{C}_{\text {nat }}=$ concentração natural do parâmetro de qualidade no manancial onde é realizado o lançamento (mg. $\mathrm{L}^{-1}$ ).

Utilizou-se o valor de 1,0 mg. $\mathrm{L}^{-1} \mathrm{O}_{2}$ conforme recomendado por von Sperling (2007) para a concentração natural de $\mathrm{DBO}_{5}$ no corpo de água, valor esse normalmente utilizado para representar a condições naturais de um rio bastante limpo. Os valores de $\mathrm{DBO}_{5}$ observados ao longo dos trechos monitorados no Taquarizinho estavam bem próximos de $1,0 \mathrm{mg} \cdot \mathrm{L}^{-1} \mathrm{O}_{2}$. A vazão indisponível no ponto de lançamento foi determinada pela Equação 3. A vazão indisponível é a soma da vazão de diluição acrescida da vazão de efluentes, contabilizando uma parcela da vazão total do rio que não poderá ser utilizada.

$\mathrm{Q}_{\text {ind }}=\mathrm{Q}_{\mathrm{dil}}+\mathrm{Q}_{\mathrm{ef}}$

Para determinar a variação das vazões de diluição após cada lançamento, mas dessa vez considerando a capacidade de autodepuração e os custos anuais (R $\$ / a n o)$ por lançamento de efluentes, foram inseridas nas planilhas em Excel as Equações 4 e 5, propostas por Silva \& Monteiro (2004):

$\mathrm{Q}_{\text {ind }}=\left(\left(\mathrm{Q}_{\mathrm{ef}}+\mathrm{Q}_{\mathrm{dil}}\right) \times \mathrm{C}_{\text {perm }} \times e^{-\mathrm{kl} . \mathrm{t}}\right) / \mathrm{C}_{\text {perm }}$

em que:

$\mathrm{Q}_{\text {ind }}=$ vazão indisponível no ponto de lançamento $\left(\mathrm{em} \mathrm{m}^{3} \cdot \mathrm{s}^{-1}\right)$;

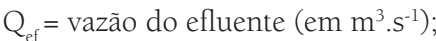

$\mathrm{k}_{1}=$ coeficiente de desoxigenação $\left(\right.$ dia $\left.^{-1}\right)$;

$\mathrm{t}=$ tempo de percurso (em dias) do trecho onde ocorre o lançamento até o trecho aonde se deseja calcular a vazão indisponível;

$\mathrm{C}_{\text {perm }}=$ concentração permitida de $\mathrm{DBO}_{5}$ para o manancial no trecho onde ocorre o lançamento;
$\mathrm{C}_{\text {perml }}=$ concentração permitida de $\mathrm{DBO}_{5}$ para o manancial no trecho onde se deseja calcular a vazão indisponível.

Custo $=\left(\mathrm{PPU} \times \mathrm{VOL}_{\text {ind }}\right) \times\left[\left(\mathrm{C}_{\text {obs }}-\mathrm{C}_{\text {nat }}\right) /\left(\mathrm{C}_{\text {perm }}-\mathrm{C}_{\text {nat }}\right)\right]$

em que:

$\mathrm{VOL}_{\text {ind }}=$ volume indisponível $\left(\mathrm{m}^{3} \cdot \mathrm{s}^{-1}\right)$;

$\mathrm{PPU}=$ preço público unitário dado em unidades monetárias por metro cúbico de vazão indisponível $\left(\mathrm{R} \$ . \mathrm{m}^{-3}\right)$;

$\mathrm{C}_{\mathrm{obs}}=$ Concentração observada no corpo hídrico do parâmetro de qualidade analisado;

$\mathrm{C}_{\text {nat }}=$ concentração natural do parâmetro de qualidade no manancial onde é realizado o lançamento.

Além das novas equações inseridas no QUAL-UFMG, o modelo utiliza as equações do QUAL2E, porém sem a modelagem de algas e considerando a dispersão longitudinal nula. A Equação 6 representa a formulação básica do modelo para o transporte de massa, em que o gradiente da concentração local está em função da dispersão, da advecção, da mudança dos constituintes, das fontes externas e diluição respectivamente (EPA, 1987).

$\frac{\partial C}{\partial t}=\frac{\partial\left(A_{x} D_{L} \frac{\partial c}{\partial x}\right)}{A_{x} \partial x}-\frac{\partial\left(A_{x} \bar{u} c\right)}{A_{x} \partial x} \frac{d c}{d t}+S / V$

em que:

$\mathrm{C}=$ concentração $\left(M \cdot \mathrm{L}^{-3}\right)$;

$\mathrm{A}_{\mathrm{x}}=$ seção transversal $\left(\mathrm{L}^{2}\right)$;

$\mathrm{D}_{\mathrm{L}}=$ coeficiente de dispersão $\left(\mathrm{L}^{2} \cdot \mathrm{T}^{-1}\right)$;

$\overline{\mathrm{UC}}=$ velocidade média $\left(\mathrm{L} \cdot \mathrm{T}^{-1}\right)$;

$\mathrm{S}=$ fontes externas de poluição $\left(\mathrm{M} \cdot \mathrm{T}^{-1}\right)$;

$\mathrm{V}=$ volume incremental $\left(\mathrm{L}^{3}\right)$.

Dessa maneira, o QUAL-UFMG além de produzir os perfis de OD e DBO ao longo do Taquarizinho, foi capaz de determinar as vazões de diluição, indisponível, disponível e os custos anuais por lançamento de efluentes visando à diluição.

\section{Simulação de cenários}

Depois de ajustados os coeficientes para o QUAL-UFMG foram simulados cenários hipotéticos futuros a partir dos quais foi possível ter uma boa estimativa da capacidade de autodepuração do Rio Taquarizinho nos quatro trechos modelados, além das vazões necessárias para a diluição de efluentes dos seis pontos de lançamentos alocados na bacia e também as vazões disponíveis para futuros processos de outorga. Para isso, foram variadas as vazões de referência no rio principal e seus afluentes $\left(Q_{95}, Q_{90}\right.$ e $Q_{m}$ ), os coeficientes calibrados em confronto com os encontrados na 
literatura, a classe de enquadramento do Taquarizinho e a concentração de $\mathrm{DBO}_{5}$ para os lançamentos de efluentes.

\section{Empreendimentos da bacia}

De acordo com as diretrizes do Zoneamento Ecológico Econômico de Mato Grosso do Sul, ZEE/MS (MATO GROSSO DO SUL, 2009), a região em estudo é dirigida à instalação de processos de inovação tecnológica, voltados à produção agrícola e agropecuária industrializada. Isso se deve à presença de recursos minerais e terras com aptidão agrícola, vulnerabilidade natural suportável, potencialidade socioeconômica favorável em termos de força de trabalho e, além disso, disponibilidade de organização empresarial e infraestrutura. Com a ideia de desenvolvimento futuro da Bacia Hidrográfica do Rio Taquarizinho, seis empreendimentos foram alocados no rio para simulação de cenários hipotéticos: um curtume, com capacidade de beneficiar 1000 peles bovinas por dia e vazão de efluentes de $0,012 \mathrm{~m}^{3} \cdot \mathrm{s}^{-1}$; três matadouros, com capacidade de abater 1000 cabeças de gado por dia cada um e vazão de efluentes de $0,030 \mathrm{~m}^{3} \cdot \mathrm{s}^{-1}$; duas estações de tratamento de esgoto para atender toda a população das cidades de São Gabriel do Oeste e Rio Verde de Mato Grosso, com vazões de 0,051 e 0,046 $\mathrm{m}^{3} \cdot \mathrm{s}^{-1}$ respectivamente. Para o cálculo das vazões foi considerado um consumo de $1000 \mathrm{~L}$ de água por pele tratada (curtume), 2500 L por cabeça abatida (matadouros) e consumo per capta de $250 \mathrm{~L}$. dia ${ }^{-1}$. hab ${ }^{-1}$ para as cidades. Em todos os casos considerou-se uma produção de efluentes em torno de $80 \%$ do consumo total de água (coeficiente de retorno de 0,8). Os valores adotados para os diversos parâmetros foram retirados de CETESB (2008).

A Figura 3 mostra o diagrama unifilar para os cenários de qualidade da água simulados.

Para estudo de caso no Rio Taquarizinho foi utilizado o seguinte cenário:

- Cenário exemplo: foi fixado o enquadramento na classe 2; os coeficientes utilizados foram os calibrados; a $\mathrm{DBO}_{5}$ dos lançamentos foi de 60 mg. $L^{-1}$ (valor máximo permitido, de acordo com a Resolução CONAMA no. 357/2005, na época do estudo); as vazões foram variadas para os regimes $\mathrm{Q}_{95}, \mathrm{Q}_{90}$ e $\mathrm{Q}_{\mathrm{m}}$. $\mathrm{O}$ objetivo desse cenário foi verificar a interferência do regime da descarga líquida nos perfis de $\mathrm{OD}$ e $\mathrm{DBO}_{5}$; nas vazões de diluição $\left(\mathrm{Q}_{\text {dil }}\right)$, vazões indisponíveis $\left(Q_{\text {ind }}\right)$ e disponíveis $\left(Q_{\text {disp }}\right)$; e custos pela diluição de efluentes.

\section{Resultados e Discussão}

\section{Determinação dos coeficientes do modelo}

Com a utilização da metodologia de regressão não linear estimou-se os coeficientes de desoxigenação $\left(k_{1}\right)$ para os quatro trechos do Rio Taquarizinho contemplados na pesquisa (Figura 4). É possível observar uma semelhança para os ajustes nos três últimos trechos,

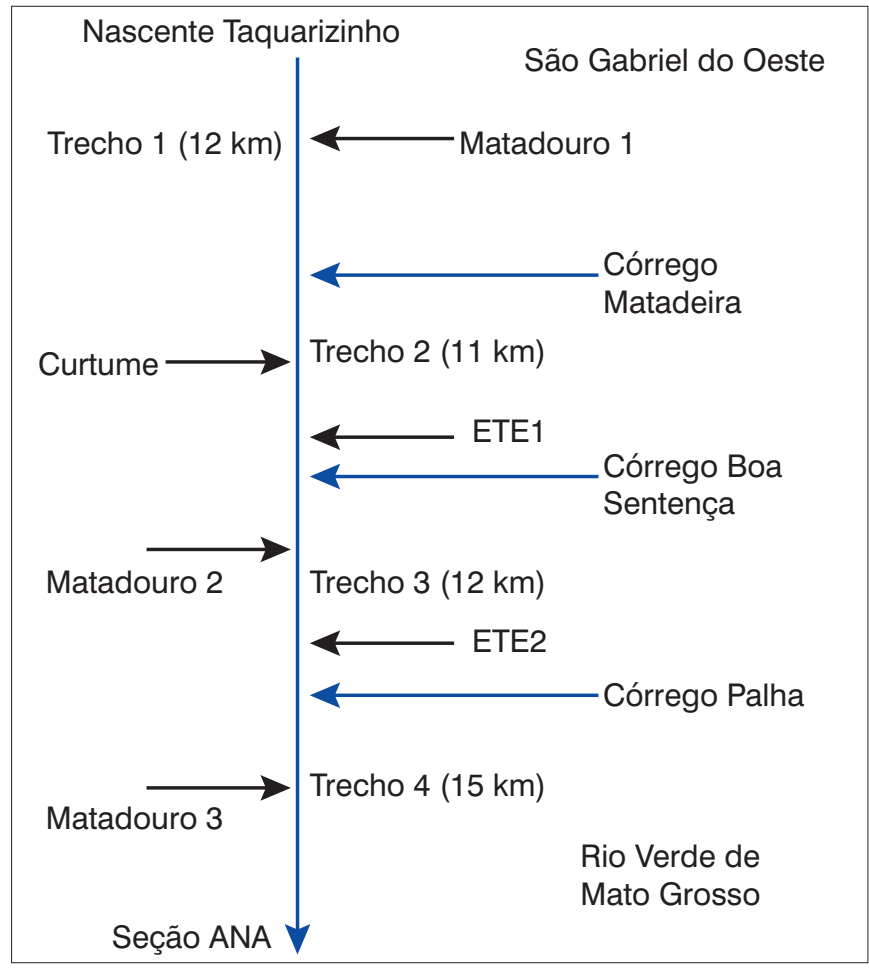

ETE: estação de tratamento de esgoto.

Figura 3 - Diagrama unifilar para o Rio Taquarizinho.

devido aos valores muito próximos de $\mathrm{DBO}$ por vários dias. A bacia do Taquarizinho encontra-se em condições muito próximas das naturais em relação à quantidade de matéria orgânica $\left(\mathrm{DBO}_{5} \mathrm{em}\right.$ torno de $\left.1 \mathrm{mg} \cdot \mathrm{L}^{-1}\right)$. Os coeficientes de correlação $\left(\mathrm{R}^{2}\right)$ encontrados estão bem próximos da unidade, mostrando um ótimo ajuste dos dados estimados aos observados (Tabela 1).

Os valores ótimos estimados para $\mathrm{k}_{1}$ (coeficiente de desoxigenação) e $\mathrm{L}_{\mathrm{o}}$ (demanda última de oxigênio) nos quatro trechos são os constantes na Tabela 1 (valores médios). Os baixos valores de $\mathrm{L}_{\mathrm{o}}$ indicam que as águas do Rio Taquarizinho possuem boa qualidade em relação à quantidade de matéria orgânica presente.

Como o coeficiente de desoxigenação é diretamente proporcional à quantidade de matéria orgânica, os baixos valores encontrados estão de acordo com o esperado. Esses valores estão bastante próximos dos valores médios tabelados encontrados na literatura técnica (VON SPERLING, 2007; CHAPRA, 1997; THOMANN \& MUELER, 1987).

A calibração de $\mathrm{k}_{\mathrm{d}}$ e $\mathrm{k}_{2}$ foi alcançada empregando-se a metodologia de otimização pelo coeficiente de determinação (CD). Como esse coeficiente varia de $-\infty$ até 1 , a ferramenta Solver faz com que o ajuste dos dados estimados aos dados observados forneça um coeficiente de determinação tendendo à unidade. Quanto mais próximo de 1 (um), melhor o ajuste requerido.

Os valores médios calibrados de $\mathrm{k}_{\mathrm{d}}$ e $\mathrm{k}_{2}$ das três campanhas estão na Tabela 2. Observa-se que os valores calibrados para $k_{d}$ são 


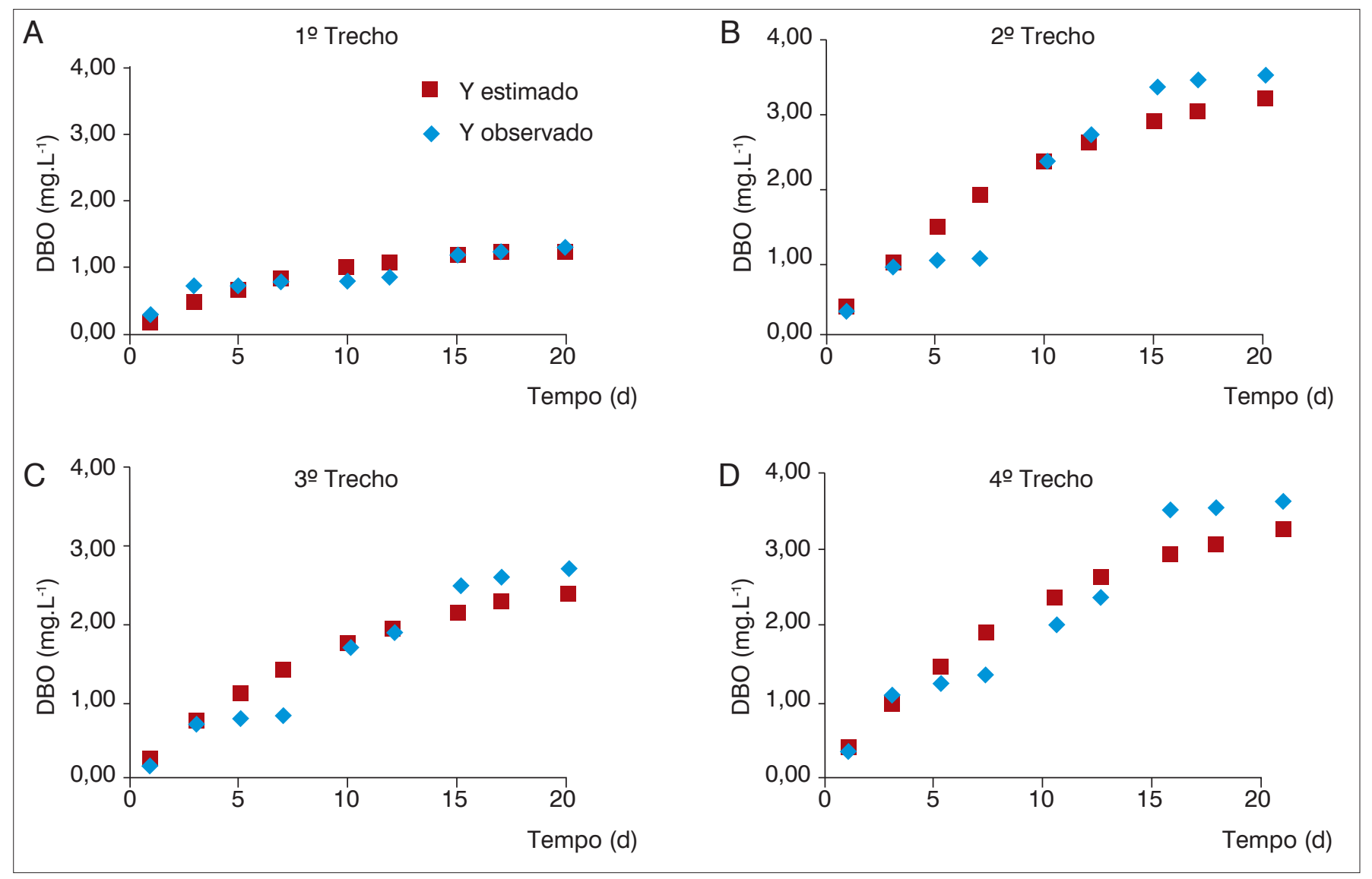

DBO: demanda bioquímica de oxigênio.

Figura 4 - Ajustes para o coeficiente de desoxigenação $\left(k_{1}\right)$ em cada trecho.

Tabela 1 - Valores médios de $\mathrm{k}_{1}$ e $\mathrm{L}_{0}$ otimizados.

\begin{tabular}{lccc} 
Trecho & $\mathbf{k}_{1}\left(\mathrm{dia}^{-1}\right)$ & $\mathrm{L}_{\mathrm{o}}\left(\mathrm{mg} \cdot \mathrm{L}^{-1}\right)$ & $\mathbf{R}^{2}$ \\
\hline 1 - Nascente - Matadeira & 0,14 & 1,60 & 0,98 \\
\hline 2 - Matadeira - Boa Sentença & 0,10 & 3,70 & 0,97 \\
\hline 3 - Boa Sentença - Palha & 0,10 & 2,84 & 0,97 \\
4 - Palha - Seção ANA & 0,10 & 3,66 & 0,97
\end{tabular}

$\mathrm{K}_{1}$ : coeficiente de desoxigenação; $\mathrm{L}_{0}$ : demanda última de oxigênio; $\mathrm{R}^{2}$ : coeficiente de relação.

Tabela 2 - Valores médios calibrados de coeficiente de decomposição e coeficiente de reaeração e respectivos coeficientes de determinação.

\begin{tabular}{lccc} 
Trecho & $\mathbf{k}_{\mathrm{d}}\left(\mathrm{dia}^{-1}\right)$ & $\mathrm{k}_{2}\left(\mathrm{dia}^{-1}\right)$ & $\mathrm{CD}$ \\
\hline 1 - Nascente - Matadeira & 0,15 & 2,70 & 0,87 \\
\hline 2 - Matadeira - Boa Sentença & 0,12 & 2,27 & 0,85 \\
3 - Boa Sentença - Palha & 0,16 & 3,05 & 0,83 \\
4 - Palha - Seção ANA & 0,15 & 2.81 & 0,85
\end{tabular}

$\mathrm{K}_{\mathrm{d}}$ : coeficiente de decomposição; $\mathrm{K}_{2}$ : coeficiente de reaeração; $C D$ : coeficiente de determinação.

muito próximos aos de $\mathrm{k}_{1}$, expostos anteriormente. Isso se justifica porque em rios com as características do Taquarizinho, de águas limpas, sem lançamento de efluentes e de pequena profundidade média, esses coeficientes possuem normalmente valores parecidos e, em muitos casos, até iguais. Quanto aos valores de $\mathrm{k}_{2}$, os resultados são característicos de rios com velocidade média baixa das águas. Se o Rio Taquarizinho possuísse velocidades maiores, já que as profundidades médias nos trechos são pequenas, os valores de $\mathrm{k}_{2}$ seriam bastante acentuados.

Um coeficiente determinação (CD) médio de 0,85 significa que com os dados usados para simulação é possível explicar uma variância em torno da média de $85 \%$ dos dados.

\section{Cenário exemplo}

A Figura 5 mostra o perfil de OD ao longo do rio, além da variação de $\mathrm{DBO}_{5}$ e porcentagem do trecho modelado que atende à legislação, com padrões de $5 \mathrm{mg} \cdot \mathrm{L}^{-1}$ para $\mathrm{OD} \mathrm{e} \mathrm{DBO}_{5}$ (classe 2) para as vazões de referência $Q_{95}, Q_{90}$ e $Q_{m}$.

É fácil verificar que o regime das três vazões utilizadas não interfere na quantidade de oxigênio dissolvido no rio, com um pequeno aumento e quase que imperceptível no final do trecho para a $Q_{m}$. Mesmo assim, a porcentagem de atendimento à legislação para os três casos permaneceu nos 90\%. Quanto à $\mathrm{DBO}_{5}$, a porcentagem de atendimento foi crescendo conforme foi aumentando a descarga 


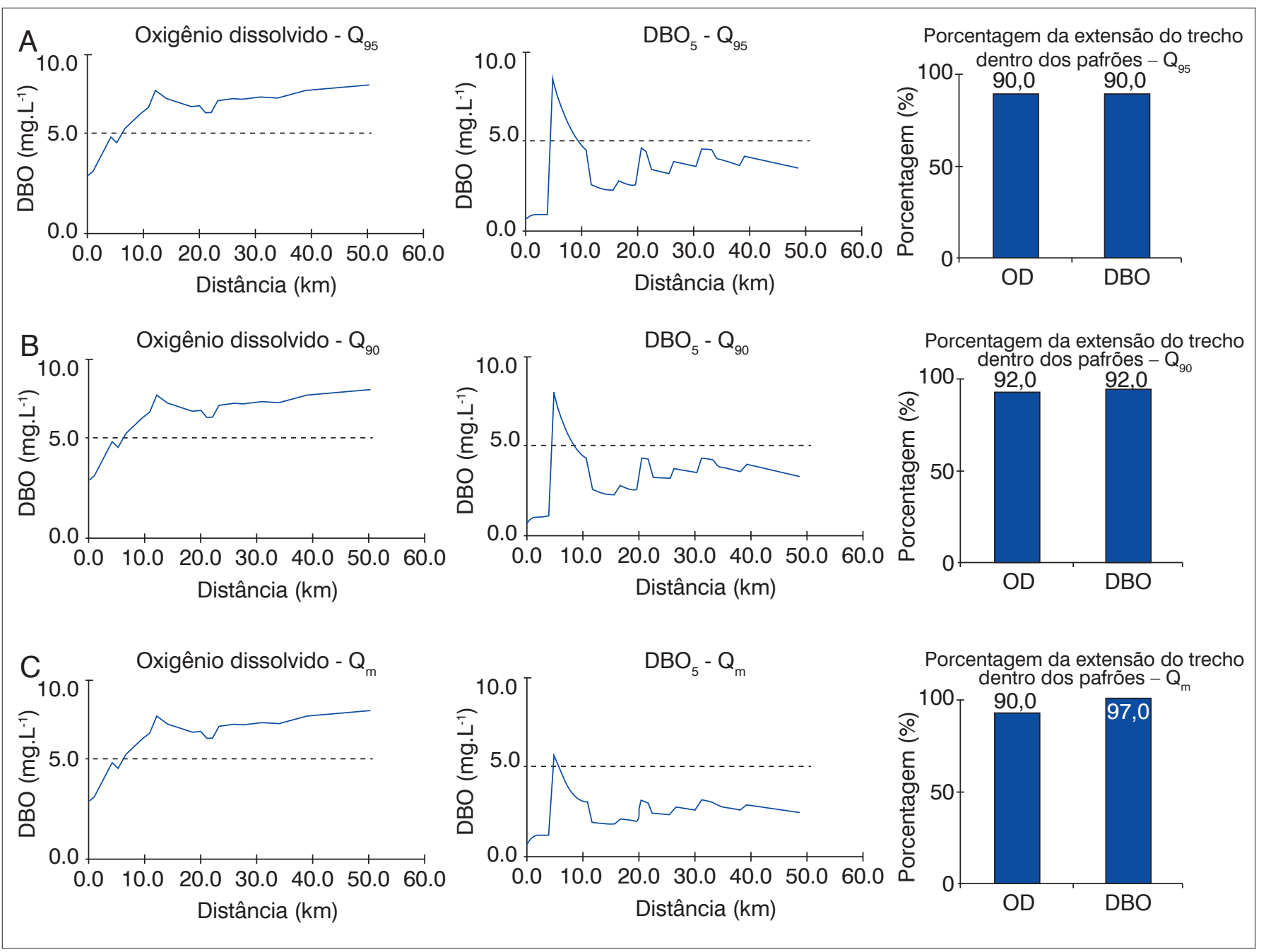

Q: vazão; OD: oxigênio dissolvido, $\mathrm{DBO}_{5}$ : demanda bioquímica de oxigênio $5 ; \mathrm{Q}_{\mathrm{m}}$ : vazão média.

Figura 5 - Perfis de oxigênio dissolvido, demanda bioquímica de oxigênio e porcentagem de atendimento aos padrões classe 2 para as vazões $Q_{95}(A), Q_{90}(B)$ e $Q_{m}(C)$.

líquida, com valores de 90, 92 e $98 \%$ para $Q_{95}, Q_{90}$ e $Q_{m}$ respectivamente. É razoável concluir que o regime de vazão tem uma maior influência no perfil de $\mathrm{DBO}_{5}$ por causa de um aumento na diluição da matéria orgânica com um maior valor de vazão. Boa parte do trecho segue dentro dos padrões requisitados na Resolução CONAMA n ${ }^{\circ}$. 357/2005, com exceção de pequena parte logo depois do primeiro lançamento, devido à sua proximidade da nascente e, por consequência, uma pequena vazão.

Na Figura 6 estão representadas em gráficos de barras as vazões de diluição, indisponível e disponível constantes nas Tabelas 3 a 5 para as três vazões de referência.

Comparando-se os valores de vazão de diluição nos três regimes é possível verificar que não houve alteração dentro da mesma condição de lançamento (considerando-se ou não os lançamentos anteriores e a autodepuração), visto que a vazão de diluição e a vazão indisponível (vazão de diluição + vazão de efluentes) não dependem do volume de água que passa numa seção. Apenas a vazão disponível (vazão total - vazão indisponível) é que variou consideravelmente, pois essa aumenta de maneira proporcional à descarga líquida, com maiores valores de disponibilidade hídrica para o regime $\mathrm{Q}_{\mathrm{m}}$. Analisando as vazões de diluição dentro do mesmo regime e considerando os lançamentos anteriores, essas aumentam consideravelmente (valores cinco vezes maiores). Com lançamentos anteriores e levando-se em conta a capacidade de autodepuração, as vazões de diluição também têm seus valores aumentados próximo de cinco vezes, porém com valores sensivelmente menores que o caso anterior por consequência da utilização do coeficiente de desoxigenação $\mathrm{k}_{1}$.

Somente no primeiro lançamento de efluentes (Matadouro 1) é que ocorreram valores negativos de vazão disponível em todos os regimes de descarga líquida. Isso significa que a vazão requerida para a diluição da carga orgânica lançada é insuficiente naquele trecho. Para os lançamentos das duas estações de tratamento de esgoto (ETE 1 e ETE 2) os valores de vazão disponível se 


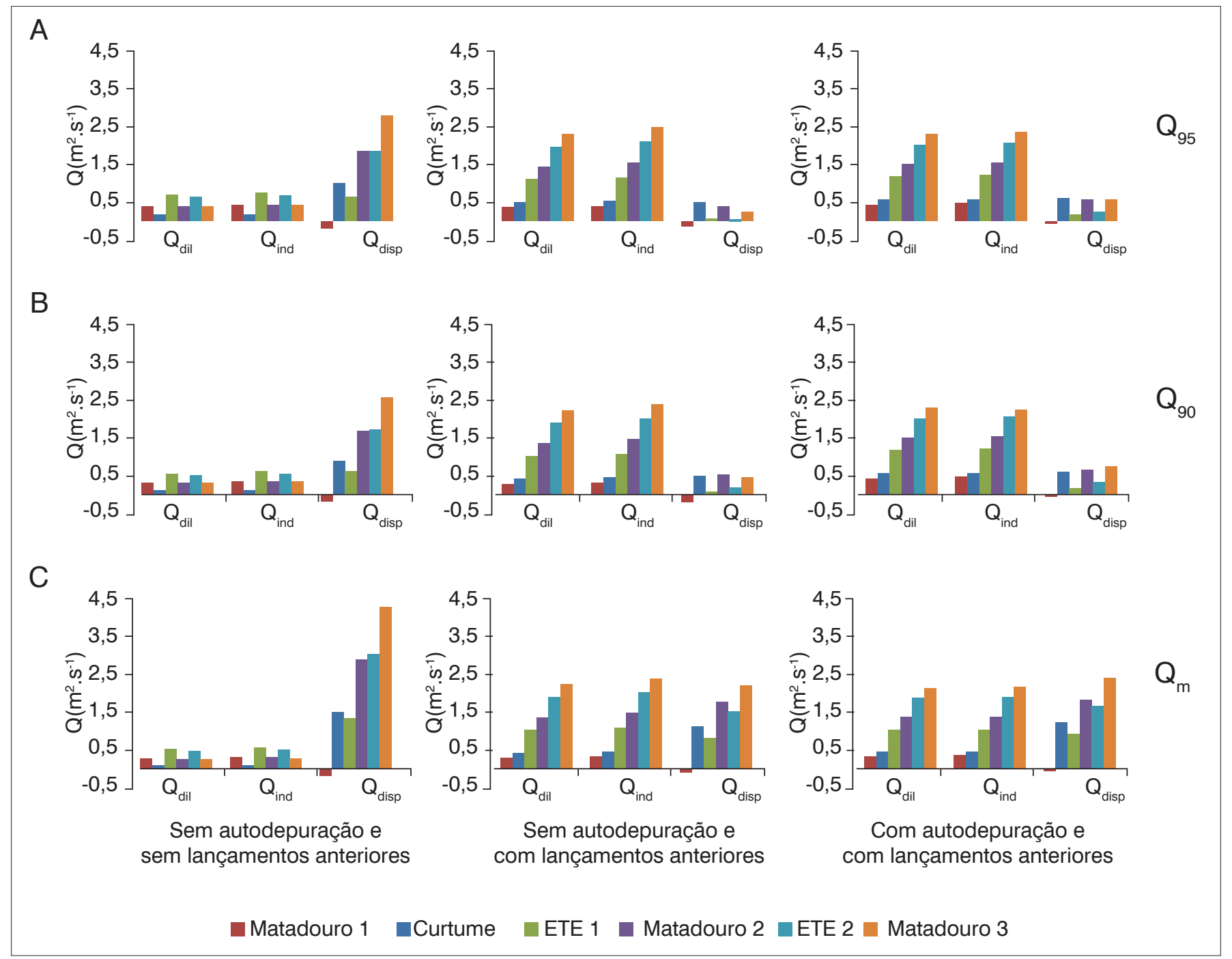

Q: vazão; $Q_{\text {dil }}$ vazão de diluição; $Q_{\text {ind }}$ : vazão indisponível; $Q_{\text {disp }}$ vazão disponível; $Q_{m}$ : vazão média.

Figura 6 - Vazões de diluição, indisponível e disponível para as vazões $Q_{95}(A), Q_{90}(B)$ e $Q_{m}(C)$ considerando-se ou não os lançamentos anteriores e a autodepuração.

aproximaram da descarga nula, indicando que o corpo receptor está no seu limite da capacidade de diluição no regime $\mathrm{Q}_{95}$ considerando os lançamentos anteriores sem autodepuração (condição mais crítica).

Na Figura 7 está representada a variação das vazões considerando-se a autodepuração e porcentagem de representação sobre a vazão de referência $\left(Q_{\text {ref }}\right)$.

Observa-se ao longo do trecho modelado o crescimento acentuado das vazões de diluição e indisponível, reflexos dos seis lançamentos de efluentes. Como a vazão média $\mathrm{Q}_{\mathrm{m}}$ possui valor bem maior que as outras de referência, a vazão disponível no cenário $Q_{m}$ se manteve quase que durante o percurso todo com valores maiores que as vazões de diluição e indisponível. Ocorrendo um lançamento, a vazão de diluição no rio tem seu valor aumentado instantaneamente e logo depois começa a decrescer devido à capacidade de autodepuração e também ao aumento de vazão que se propaga de montante para jusante. Apenas no primeiro lançamento para os três regimes é que a vazão de diluição ultrapassou os 50\% do que é normalmente outorgado da vazão de referência pelos órgãos responsáveis pelo gerenciamento de recursos hídricos. Logo após o primeiro lançamento, a porcentagem se mantém abaixo dos $50 \%$ se não forem considerados os lançamentos anteriores para os cenários de $Q_{95}$ e $Q_{90}$. Para $Q_{m}$, mesmo considerando os lançamentos anteriores, a vazão de diluição se manteve abaixo dos 50\% em todo o percurso após o primeiro lançamento. Dessa maneira, deduz-se que o fato de se considerar os lançamentos anteriores na determinação das vazões de diluição é de grande importância para as condições críticas de vazão $\left(Q_{95}\right.$ e $\left.Q_{90}\right)$.

Os custos foram determinados atribuindo o valor de 0,001 $\mathrm{R} \$ . \mathrm{m}^{-3}$ de efluentes lançados. Para as condições hipotéticas 
Tabela 3 - Vazões de diluição, indisponível e disponível para $Q_{95}$.

\begin{tabular}{|c|c|c|c|c|c|c|c|}
\hline \multirow{3}{*}{ Lançamentos } & \multirow{3}{*}{ Distância (km) } & \multicolumn{3}{|c|}{ Sem lançamentos anteriores } & \multicolumn{3}{|c|}{ Com lançamentos anteriores } \\
\hline & & $Q_{\text {dil }\left(m^{3} \cdot s^{-1}\right)}$ & $Q_{\text {ind (m?.s') }}$ & $Q_{\text {disp (m?.s.) }}$ & $Q_{\text {dil }\left(m^{3} s^{\prime}\right)}$ & $Q_{\left.\text {ind (m? } s^{\prime}\right)}$ & $Q_{\text {disp (m3.s. })}$ \\
\hline & & \multicolumn{6}{|c|}{ Sem considerar a capacidade de autodepuração $-Q_{95}$} \\
\hline Matadouro 1 & 5 & 0,412 & 0,442 & $-0,212$ & 0,412 & 0,442 & $-0,212$ \\
\hline Curtume & 17 & 0,165 & 0,177 & 0,992 & 0,577 & 0,619 & 0,549 \\
\hline ETE 1 & 21 & 0,701 & 0,752 & 0,639 & 1,278 & 1,371 & 0,020 \\
\hline Matadouro 2 & 27 & 0,412 & 0,442 & 1,825 & 1,691 & 1,814 & 0,453 \\
\hline ETE 2 & 32 & 0,632 & 0,678 & 1,835 & 2,323 & 2,492 & 0,021 \\
\hline \multirow[t]{2}{*}{ Matadouro 3} & 40 & 0,412 & 0,442 & 2,771 & 2,736 & 2,935 & 0,278 \\
\hline & & \multicolumn{6}{|c|}{ Considerando a capacidade de autodepuração $-Q_{95}$} \\
\hline Matadouro 1 & 5 & 0,412 & 0,442 & $-0,212$ & 0,412 & 0,442 & $-0,212$ \\
\hline Curtume & 17 & 0,165 & 0,177 & 0,992 & 0,560 & 0,572 & 0,596 \\
\hline ETE 1 & 21 & 0,701 & 0,752 & 0,639 & 1,263 & 1,314 & 0,077 \\
\hline Matadouro 2 & 27 & 0,412 & 0,442 & 1,825 & 1,684 & 1,714 & 0,553 \\
\hline ETE 2 & 32 & 0,632 & 0,678 & 1,835 & 2,302 & 2,348 & 0,165 \\
\hline Matadouro 3 & 40 & 0,412 & 0,442 & 2,771 & 2,643 & 2,673 & 0,540 \\
\hline
\end{tabular}

$\mathrm{Q}_{\mathrm{dil}}$ : vazão de diluição; $Q_{\text {ind }}$ : vazão indisponível; $Q_{\text {disp }}$ : vazão disponível.

Tabela 4 - Vazões de diluição, indisponível e disponível para $Q_{90}$.

\begin{tabular}{|c|c|c|c|c|c|c|c|}
\hline \multirow{3}{*}{ Lançamentos } & \multirow{3}{*}{ Distância (km) } & \multicolumn{3}{|c|}{ Sem lançamentos anteriores } & \multicolumn{3}{|c|}{ Com lançamentos anteriores } \\
\hline & & $Q_{\text {dil }\left(m^{3} . s^{-1}\right)}$ & $Q_{\text {ind (ms.') }}$ & $Q_{\text {disp (m3.s. }}$ & $Q_{\text {dil (m.s.s.) }}$ & $Q_{\text {ind }\left(m^{3} \cdot s^{1}\right)}$ & $Q_{\text {disp (ms.s.) }}$ \\
\hline & & \multicolumn{6}{|c|}{ Sem considerar a capacidade de autodepuração $-Q_{90}$} \\
\hline Matadouro 1 & 5 & 0,412 & 0,442 & $-0,192$ & 0,412 & 0,442 & $-0,192$ \\
\hline Curtume & 17 & 0,165 & 0,177 & 1,110 & 0,577 & 0,619 & 0,667 \\
\hline ETE 1 & 21 & 0,701 & 0,752 & 0,773 & 1,278 & 1,371 & 0,154 \\
\hline Matadouro 2 & 27 & 0,412 & 0,442 & 2,053 & 1,691 & 1,814 & 0,681 \\
\hline ETE 2 & 32 & 0,632 & 0,678 & 2,083 & 2,323 & 2,492 & 0,269 \\
\hline \multirow[t]{2}{*}{ Matadouro 3} & 40 & 0,412 & 0,442 & 3,096 & 2,736 & 2,935 & 0,603 \\
\hline & & \multicolumn{6}{|c|}{ Considerando a capacidade de autodepuração $-Q_{90}$} \\
\hline Matadouro 1 & 5 & 0,412 & 0,442 & $-0,192$ & 0,412 & 0,442 & $-0,192$ \\
\hline Curtume & 17 & 0,165 & 0,177 & 1,110 & 0,560 & 0,572 & 0,714 \\
\hline ETE 1 & 21 & 0,701 & 0,752 & 0,773 & 1,263 & 1,314 & 0,211 \\
\hline Matadouro 2 & 27 & 0,412 & 0,442 & 2,053 & 1,684 & 1,714 & 0,781 \\
\hline ETE 2 & 32 & 0,632 & 0,678 & 2,083 & 2,302 & 2,348 & 0,413 \\
\hline Matadouro 3 & 40 & 0,412 & 0,442 & 3,096 & 2,643 & 2,673 & 0,865 \\
\hline
\end{tabular}

$\mathrm{Q}_{\mathrm{dil}}$ : vazão de diluição; $Q_{\text {ind }}$ : vazão indisponível; $Q_{\text {disp }}$ : vazão disponível.

Tabela 5 - Vazões de diluição, indisponível e disponível para $Q_{m}$.

\begin{tabular}{|c|c|c|c|c|c|c|c|}
\hline \multirow{3}{*}{ Lançamentos } & \multirow{3}{*}{ Distância (km) } & \multicolumn{3}{|c|}{ Sem lançamentos anteriores } & \multicolumn{3}{|c|}{ Com lançamentos anteriores } \\
\hline & & $Q_{\text {dil }\left(m^{3} \cdot s^{\prime}\right)}$ & $Q_{\text {ind }\left(m^{3} s^{-1}\right)}$ & $Q_{\left.\text {disp (m? } \mathrm{s}^{1}\right)}$ & $Q_{\text {dil }\left(m^{3}, s^{\prime}\right)}$ & $Q_{\text {ind }\left(m^{3} s^{\prime}\right)}$ & $Q_{\text {disp (m?.s') }}$ \\
\hline & & \multicolumn{6}{|c|}{ Sem considerar a capacidade de autodepuração $-Q_{m}$} \\
\hline Matadouro 1 & 5 & 0,412 & 0,442 & $-0,062$ & 0,412 & 0,442 & $-0,062$ \\
\hline ETE 1 & 21 & 0,701 & 0,752 & 1,685 & 1,278 & 1,371 & 1,066 \\
\hline Matadouro 2 & 27 & 0,412 & 0,442 & 3,557 & 1,691 & 1,814 & 2,185 \\
\hline Matadouro 3 & & \multicolumn{6}{|c|}{ Considerando a capacidade de autodepuração $-Q_{m}$} \\
\hline Matadouro 1 & 5 & 0,412 & 0,442 & $-0,062$ & 0,412 & 0,442 & $-0,062$ \\
\hline Curtume & 17 & 0,165 & 0,177 & 1,902 & 0,560 & 0,572 & 1,506 \\
\hline ETE 1 & 21 & 0,701 & 0,752 & 1,685 & 1,263 & 1,314 & 1,123 \\
\hline Matadouro 2 & 27 & 0,412 & 0,442 & 3,557 & 1,684 & 1,714 & 2,285 \\
\hline
\end{tabular}

$\mathrm{Q}_{\mathrm{dil}}$ : vazão de diluição; $Q_{\text {ind: }}$ vazão indisponível; $Q_{\text {disp }}$ : vazão disponível; $Q_{m}$ : vazão média. 

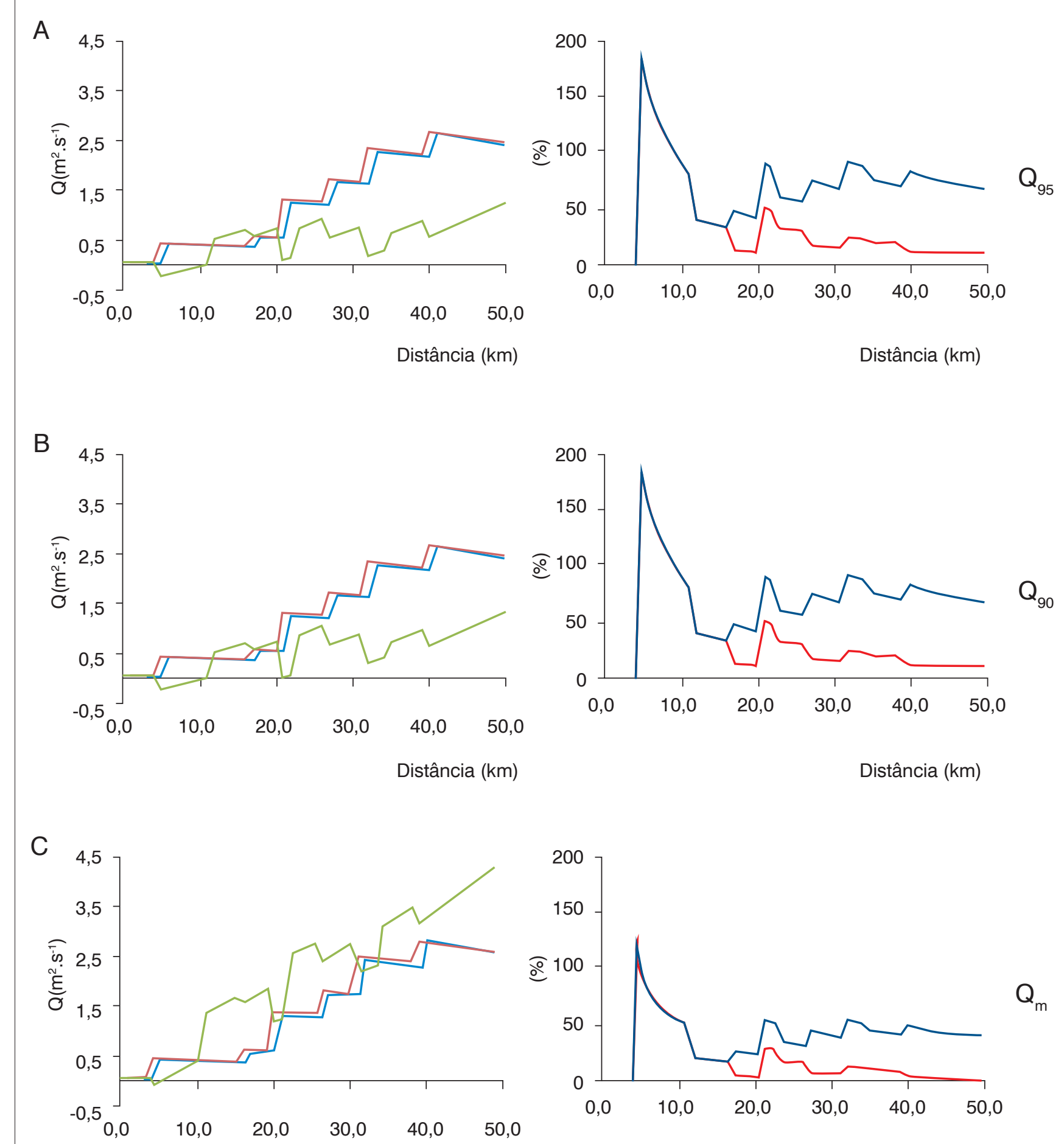

Distância (km)

— Vazão diluição

— Vazão indisponível

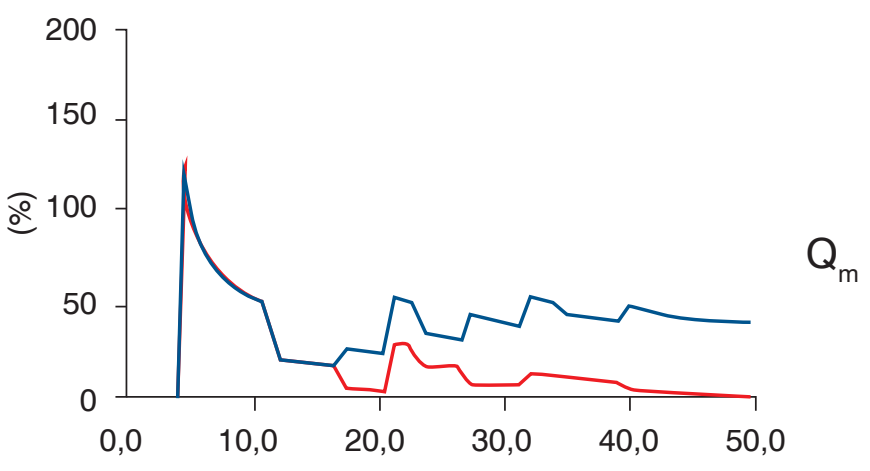

— Vazão disponível

Distância (km)

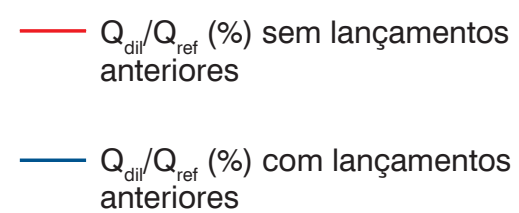

Q: vazão; $Q_{\mathrm{dil}}$ vazão de diluição; $Q_{\mathrm{ret}}$ v vazão de referência; $Q_{\mathrm{m}}$ : vazão média.

Figura 7 - Comportamento das vazões de diluição, indisponível e disponível considerando a autodepuração e porcentagens da vazão de diluição sobre a de referência. 
simuladas, os valores totais anuais de custo para lançamento foram bem pequenos se comparados com a arrecadação de algumas bacias no país que alcançam um total anual da ordem de milhões de Reais. A Tabela 6 apresenta os valores dos custos por lançamento com total anual e suas representações gráficas estão na Figura 8.

Tabela 6 - Custos anuais por lançamento nas classes 1, 2 e 3.

\begin{tabular}{|c|c|c|c|}
\hline \multirow{2}{*}{ Lançamentos } & Situação 1 & Situação 2 & Situação 3 \\
\hline & Custo $\left(\mathrm{R} \$ . \mathrm{ano}^{-1}\right)$ & Custo $\left(\mathrm{R} \$ . \mathrm{ano}^{-1}\right)$ & Custo $\left(\mathrm{R} \$ . \mathrm{ano}^{-1}\right)$ \\
\hline \multicolumn{4}{|l|}{ Classe 1} \\
\hline Matadouro 1 & $13.954,68$ & $13.954,68$ & $13.954,68$ \\
\hline Curtume & $5.581,87$ & $19.536,55$ & $18.059,45$ \\
\hline ETE 1 & $23.722,95$ & $43.259,50$ & $41.452,18$ \\
\hline Matadouro 2 & $13.954,68$ & $57.214,18$ & $54.056,29$ \\
\hline ETE 2 & $21.397,17$ & $78.611,36$ & $74.064,76$ \\
\hline Matadouro 3 & $13.954,68$ & $92.566,04$ & $84.320,06$ \\
\hline Total (R\$/ano) & $92.566,04$ & $305.142,33$ & $285.907,44$ \\
\hline \multicolumn{4}{|l|}{ Classe 2} \\
\hline Matadouro 1 & 3.488 .67 & $3.488,67$ & $3.488,67$ \\
\hline Curtume & $1.395,46$ & $4.884,13$ & $4.514,86$ \\
\hline ETE 1 & $5.930,73$ & $10.814,87$ & $10.363,04$ \\
\hline Matadouro 2 & $3.488,67$ & $14.303,54$ & $13.514,07$ \\
\hline ETE 2 & $5.349,29$ & $19.65,84$ & $18.516,19$ \\
\hline Matadouro 3 & $3.488,67$ & $23.141,51$ & $21.080,01$ \\
\hline Total (R\$/ano) & $23.141,51$ & $76.285,58$ & $71.476,86$ \\
\hline \multicolumn{4}{|l|}{ Classe 3} \\
\hline Matadouro 1 & 689,12 & 689,12 & 689,12 \\
\hline Curtume & 275,64 & 964,76 & 891,82 \\
\hline ETE 1 & $1.171,50$ & $2.136,27$ & $2.047,02$ \\
\hline Matadouro 2 & 689,12 & $2.825,39$ & $2.669,44$ \\
\hline ETE 2 & $1.056,65$ & $3.882,04$ & $3.657,51$ \\
\hline Matadouro 3 & 689,12 & $4.571,16$ & $4.163,95$ \\
\hline Total (R\$/ano) & $4.571,16$ & $15.068,75$ & $14.118,88$ \\
\hline
\end{tabular}

ETE: estação de tratamento de esgoto.
A variação de custo total da condição mais restrita (classe 1) para a menos restrita (classe 3), em qualquer situação de lançamento foi de 4 vezes maior para a classe 1 do que para a classe 2 e 20 vezes maior para a classe 1 do que para a classe 3. Os resultados mostram que se a concentração permitida no rio for reduzida em $2 / 3$, de $10 \mathrm{mg} . \mathrm{L}^{-1}$ para $3 \mathrm{mg} . \mathrm{L}^{-1}$ (classe 3 para classe 1), o valor anual cobrado pelos lançamentos na bacia aumenta em 20 vezes.

Uma grande mudança nos custos foi verificada pela consideração dos lançamentos anteriores, com aumento considerável no custo anual para as três classes de enquadramento. Dessa maneira, a bacia "deixa de arrecadar" um montante bem maior para uso no gerenciamento dos recursos hídricos. O custo só aumentou dessa maneira porque a vazão indisponível aumentou ao longo do rio em consequência dos lançamentos anteriores. É como se o usuário de jusante pagasse pela degradação produzida pelo lançamento a montante.

$\mathrm{Na}$ mesma classe, o custo anual pelos lançamentos na bacia é aumentado em três vezes se forem considerados os lançamentos anteriores, com ou sem a autodepuração. Novamente, os lançamentos anteriores exercem maior influência no custo total pela diluição de efluentes que a capacidade de autodepuração para essas condições simuladas. Os valores dos custos iniciais são iguais na mesma classe porque antes do Matadouro 1 não existem lançamentos, e assim o volume indisponível é igual para as condições simuladas. O parâmetro responsável pela variação de valores em cada classe para o primeiro lançamento é a concentração permitida de $\mathrm{DBO}_{5}\left(\mathrm{C}_{\text {perm }}\right)$.

\section{Conclusões}

Apesar da intensa atividade agropecuária na bacia do Rio Taquarizinho, o mesmo ainda apresenta uma boa qualidade em suas águas, baseando-se em valores de DBO e OD. O período crítico de monitoramento, com vazões mínimas, sugere uma boa capacidade suporte do rio para a instalação de empreendimentos na bacia.

\begin{tabular}{|c|c|c|c|c|c|c|c|}
\hline \multicolumn{2}{|c|}{ Custo (R\$) } & \multicolumn{2}{|c|}{ Custo $(\mathrm{R} \$)$} & \multicolumn{4}{|c|}{ Custo $(\mathrm{R} \$)$} \\
\hline 90000 & \multirow[b]{2}{*}{ Classe 1} & 90000 & & \multirow{2}{*}{$\begin{array}{l}90000 \\
70000\end{array}$} & \multirow{2}{*}{\multicolumn{3}{|c|}{ Classe 2}} \\
\hline 70000 & & 70000 & Classe 2 & & & & \\
\hline 50000 & & \multicolumn{2}{|l|}{50000} & 50000 & & & \\
\hline 30000 & & \multicolumn{2}{|l|}{30000} & 30000 & & & \\
\hline 10000 & & \multicolumn{2}{|c|}{10000} & 10000 & & & \\
\hline & A & & A & & A & B & C \\
\hline \multicolumn{2}{|c|}{$\begin{array}{l}\text { A - Sem autodepuração e } \\
\text { sem lançamentos anteriores }\end{array}$} & \multicolumn{2}{|r|}{$\begin{array}{l}\text { B - Sem autodepuração mas } \\
\text { com lançamentos anteriores }\end{array}$} & \multicolumn{4}{|c|}{$\begin{array}{l}\text { C - Com autodepuração e } \\
\text { com lançamentos anteriores }\end{array}$} \\
\hline & Matadouro 1 & urtume & ETE 1 Matadouro 2 & $2 \square M$ & atadour & & \\
\hline
\end{tabular}

ETE: estação de tratamento de esgoto.

Figura 8 - Custos anuais para as 3 classes de enquadramento considerando ou não a autodepuração e lançamentos anteriores. 
Sabe-se que é muito difícil tratar efluentes a ponto de conseguir lançar uma concentração muito próxima da permitida no corpo de água. Porém, isso talvez possa ser vantajoso para o usuário no sentido de reduzir os custos pagos pela diluição de efluentes. Dependendo das características do efluente e também das condições que se encontra o rio com o enquadramento, pode ser mais economicamente viável investir numa maior eficiência de tratamento do que pagar um pouco mais pela diluição. Uma análise econômica poderá fazer um balanço entre investir para aumentar a eficiência de tratamento e lançar uma maior carga de poluentes a um custo maior pela diluição, de maneira que se encontre uma solução equilibrada e otimizada para o problema.

É interessante ressaltar que, de acordo com as condições simuladas para esse trabalho, a consideração dos lançamentos anteriores é de extrema importância para a determinação das vazões de diluição e consequente disponibilidade hídrica. Porém, os lançamentos anteriores não devem ser considerados na determinação dos custos pela diluição de efluentes porque, dessa maneira, usuários de jusante estariam pagando por uma indisponibilidade hídrica que não foi devida ao seu lançamento.

A sugestão de uma metodologia de outorga para lançamento de efluentes no Rio Taquarizinho deverá ser baseada em experiências e metodologias que estão sendo aplicadas por alguns comitês de bacia de outros estados e órgãos gestores de recursos hídricos. Basicamente, ela deverá se apoiar em uma análise da capacidade de autodepuração do rio, com o intuito de alocar de maneira otimizada as vazões de diluição respeitando a classe de enquadramento. Se em algum ponto a vazão disponível para outorga for inferior à requerida para diluição de efluentes, sugere-se determinar a redução de carga necessária ou então outra localização ao longo do curso de água com disponibilidade hídrica.

As equações inseridas no modelo QUAL-UFMG foram capazes de representar as condições prevalecentes de qualidade da água e quantificação de vazões requeridas pelo lançamento de efluentes. Dessa maneira, o modelo foi complementado no intuito de fornecer maiores informações para o gerenciamento de recursos hídricos.

\section{Referências}

APHA - American Public Health Association; AWWA - American Water Works Association; WEF - Water Environment Federation. Standard Methods for the Examination of Water and Wastewater. 21 ed., Washington, 2005

BRASIL. Ministério do Meio Ambiente. (1997) Lei n. 9.433, de 08 de janeiro de 1997. Política Nacional dos Recursos Hídricos. Diário Oficial da União. Brasília, DF: Imprensa Oficial.

BRASIL. Conselho Nacional de Recursos Hídricos. (2001) Resolução CNRH n. 48, de 21 de março de 2005. Diário Oficial da União. Brasília, DF: Imprensa Oficial.

BRASIL. Conselho Nacional de Meio Ambiente. (2005) Resolução CONAMA n. 357, de 17 de maio de 2005. Diário Oficial da União. Brasília, DF: Imprensa Oficial.

SILVA, L.M.C. \& MONTEIRO, R.A. (2004) Outorga de direito de uso de recursos hídricos: uma das possíveis abordagens. In: MACHADO, C.J.S. Gestão de águas doces. Rio de Janeiro: Interciência, p. 135-178.

CETESB - Companhia Ambiental do Estado de São Paulo. (2008) Guia técnico ambiental de abate (bovino e suíno) - Série P + L. São Paulo: CETESB.

CHAPRA, S.C. Surface Water Quality Modeling. New York: WCB/McGrawHill, 1997. 844 p.
DA-PING, X.; HONG-YU, G.; DAN, H. (2011) Discussion on the Demand management of water resources. Procedia Environmental Sciences, v. 10, p. 1173-1176.

DNAEE - Departamento Nacional de Águas e Energia Elétrica. (1977) Manual para serviços de hidrometria. São Paulo: DNAEE.

EPA - United States Environmental Protection Agency. (1987) The enhanced stream water quality models QUAL2E and QUAL2E-UNCAS Documentation and user model. Athens, $189 \mathrm{p}$.

KELMAN, J. (1997) Gerenciamento de recursos hídricos: outorga e cobrança. In: Simpósio Brasileiro de Recursos Hídricos, 12. Anais... Vitória.

LARENTIS, D.G. (2004) Modelagem matemática da qualidade da água em grandes bacias: sistema Taquari-Antas - RS. Dissertação (Mestrado) em Engenharia. Universidade Federal do Rio Grande do Sul, Porto Alegre, $159 \mathrm{p}$

LOPES, J.F.; SILVA, C.I.; CARDOSO, A.C. (2008) Validation of a water quality model for the Ria de Aveiro lagoon, Portugal. Environmental Modelling \& Software, v. 23, p. 479-494.

MATO GROSSO DO SUL. Secretaria de Estado do Meio Ambiente, das Cidades, do Planejamento, da Ciência e Tecnologia (SEMAC). (2009) Zoneamento ecológico econômico de Mato Grosso do Sul. Campo Grande. 
PAREDES, J.; ANDREU, J.; SOLERA, A. (2010) A decision support system for water quality issues in the Manzanares River (Madrid, Spain). Science of the Total Environment v. 408, p. 2576-2589.

RIBEIRO, M.M. \& LANNA, A.E. (2003) A Outorga Integrada das Vazões de Captação e Diluição. Revista Brasileira de Recursos Hídricos. v. 8, p. 151-168.

RODRIGUES, R.B. (2005) Sistema de suporte a decisão proposta para a gestão quali-quantitativa dos processos de outorga e cobrança pelo uso da água. Tese (Doutorado). Universidade de São Paulo, São Paulo, $152 \mathrm{p}$.

THOMANN, R.V. \& MUELLER, J.A. Principles of surface water quality modeling and control. Harper International edition, 1987, 644 p.

VON SPERLING, M. (2007) Estudos e modelagem da qualidade da água de rios. Belo Horizonte: Departamento de Engenharia Sanitária e Ambiental; Universidade Federal de Minas Gerais, $587 \mathrm{p}$. 